\title{
Field surveys of capercaillie (Tetrao urogallus) in the Swiss Alps underestimated local abundance of the species as revealed by genetic analyses of non-invasive samples
}

\author{
Gwenaël Jacob · Rolf Debrunner · Felix Gugerli • \\ Bernhard Schmid · Kurt Bollmann
}

Received: 13 August 2008/Accepted: 17 December 2008/Published online: 11 January 2009

(C) Springer Science+Business Media B.V. 2009

\begin{abstract}
An increasing number of species are becoming threatened by habitat loss and fragmentation. Therefore, solid estimates of the species' abundance in the remaining populations are required to develop suitable conservation measures and to monitor their effectiveness. The capercaillie (Tetrao urogallus L.) has experienced a dramatic decline in central Europe and has disappeared from large areas of its former natural range. In Switzerland, the species' distribution, habitat requirements and demographic status were studied and evaluated in an attempt to support appropriate management decisions to conserve the species. National surveys of the capercaillie in Switzerland have traditionally been obtained from male counts at leks. However, individual attendance to the lek is sex- and agespecific. Thus, male counts at leks may provide a biased estimate of local population sizes. In the present study, we compared two alternative indirect methods to estimate the sizes of local populations at eight study sites situated in the Alps and Prealps of Switzerland. We first assessed the sizes of local populations from the observed density and distribution of direct and indirect evidence of the species' presence during field surveys. Feather and faeces samples collected during field surveys were genotyped at twelve nuclear microsatellite loci and a sex-specific nuclear gene fragment. Individual genotypes were used as genetic tags to estimate the sizes of the eight local populations using an
\end{abstract}

G. Jacob · R. Debrunner · F. Gugerli $(\bowtie)$ - K. Bollmann Biodiversity and Conservation Biology, WSL Swiss Federal Research Institute, Zürcherstrasse 111, 8903 Birmensdorf, Switzerland

e-mail: felix.gugerli@wsl.ch

G. Jacob · B. Schmid

Institute of Environmental Sciences, University of Zürich,

Zürich, Switzerland urn model developed for small populations. The index of local population sizes assessed from field surveys was lower than the number of unique genotypes at each study site, which itself underestimated the abundances of populations in most cases. Based on our results, the genetic tagging method appeared to be less biased than the field survey method. However, an alternative faeces sampling scheme, resulting in 2-3 genotypings per individual, could further improve the accuracy of the size estimates of local populations. Our study confirms that genetic tagging methods are a valuable tool to estimate the sizes of local populations and to monitor the response of rare and elusive species to management actions.

Keywords Abundance estimate - Capercaillie . Genetic tagging $\cdot$ Non-invasive sampling

\section{Introduction}

An increasing number of species live in fragmented habitats and face a high risk of local extinction owing to demographic processes, environmental stochastic events, or genetic erosion (Allendorf and Luikart 2007). Therefore, reliable estimates of species living in remnant habitat patches have become a major issue for monitoring the status and demography of endangered species particularly in response to management action (Franzreb 1997; Maschinski et al. 1997; Fisher et al. 2000; Fujiwara and Caswell 2001; Banks et al. 2003).

Conventional capture-mark-recapture (CMR) studies have been commonly used to estimate the sizes of wild populations (reviewed in Schwarz and Seber 1999). However, their invasive approach renders them inappropriate for the study of rare or elusive species. The advancement of 
genetic techniques made it possible to use various types of material deposited by individuals in the field (e.g. hair, feathers, faeces) as sources of DNA and to distinguish among individuals based on their genotypes (Morin et al. 1993; Gerloff et al. 1995; Gagneux et al. 1997; Taberlet and Luikart 1999; Segelbacher 2002). These data are then incorporated into a statistical framework analogous to conventional CMR methods, which is why the terminology has been adopted also for non-invasive capture/recapture. Because the proper detection of unique multi-locus genotypes is mandatory for reliable population size estimates, several constraints have to be considered. (1) Declining and small populations generally show low levels of allelic diversity, which increases the probability that two individuals within the population share the same multi-locus genotype (Mills et al. 2000). (2) The lack of power to discriminate among genetically similar individuals in such populations may result in considering an individual not previously captured, but with an already known multi-locus genotype, as a recapture event. (3) Moreover, taking DNA from non-invasive samples bears greater risks of genotyping errors than invasive samples such as blood. Because of the generally low quantity and quality of DNA extracted from non-invasive samples and used as template in the polymerase chain reaction (PCR), allelic dropout may occur, i.e. one of the two alleles at a locus of a heterozygous individual may not be detected (Gagneux et al. 1997). Scoring false alleles (PCR-generated alleles, Taberlet et al. 1996) or non-target fragments (Bradley and Vigilant 2002) are other potential sources of genotyping errors. Thus, false genotypes may occur which are recorded as new capture events instead of recaptures. Methodological improvements have been proposed that reduce the risk of genotyping errors, such as scoring alleles based on several PCR replicates (Navidi et al. 1992; Taberlet et al. 1996; Goossens et al. 2000; Hansen et al. 2008).

Using biased indices or estimates of population sizes may lead to inappropriate management scenarios such as to engage human and financial resources in conservation programs for populations that are not currently threatened. The consequences may be more severe if no management actions were planned because the population sizes were overestimated. In all cases, the demographic response of populations to management scenarios may remain undetected if biased and inaccurate indices or estimates are used. The minimum number of individuals alive (MNA) in a population, obtained by enumerating the unique multi-locus genotypes, provides a first approximation of the size of a population, although this measure is biased towards low values in most situations (Mills et al. 2000). The CMR framework allows the integration of covariates, e.g. age, sex or behavioural traits, in the estimation of the probability of capture and population size, and may therefore outperform conventional methods such as field surveys (FS) (Bellemain et al. 2005; Lukacs and Burnham 2005a, b). CMR models require at least two sampling events in a population (one for marking and one for recapturing) and thus potentially increase the disturbance for the species (the disturbance could be maintained low if the data are collected noninvasively). Models have been developed to estimate population sizes from data collected in a single sampling session, adopted for the study of rare, elusive or endangered species (Kohn et al. 1999; Eggert et al. 2003; Wilson et al. 2003; Frantz et al. 2004; Miller et al. 2005). Kohn et al. (1999) and Eggert et al. (2003) assessed the size of wild populations by calculating the asymptotic value of accumulation curves fitted to the plots of the number of unique individuals observed when sampling without replacement among all the genotypes identified. Valière (2002) used an urn model without replacement and the assumption of an even probability of capture among individuals. Miller et al. (2005) described a likelihood function that allows for integrating different probabilities of capture among individuals within a population. Simulation and empirical studies showed that urn models outperform extrapolation models in estimating the sizes of small populations (Wilson et al. 2003; Miller et al. 2005), which are of greatest conservation concern.

Bromaghin (2007) criticized the methodology of Miller et al. (2005) because the function implemented in the software CAPWIRE assumes that the observations of the unique individuals are arbitrarily ordered prior to analysis. The corrected function proposed by Bromaghin (2007) includes an additional term that counts the number of ways the observed individuals can be uniquely arranged. Because this term does not involve $N$, the estimated population size, the corrected formula provides similar results to those of CAPWIRE (Bromaghin 2007; Miller et al. 2007).

The capercaillie (Tetrao urogallus L.) is a large grouse species with its main distribution range in the boreal forests of Scandinavia and Russia. The species also occurs in temperate zones where it is restricted to the mountainous areas covered with coniferous uneven-aged forests in western and central Europe (Storch 2001). Changes in silvicultural practice and increasing human disturbance resulting from recreational use of the forested areas have led to a substantial reduction in suitable habitat during the twentieth century (Bollmann et al. 2008). Consequently, the species' occurrences have become fragmented in Scandinavia (Helle et al. 1994) and central Europe, especially in lowland areas (Storch 2000, 2001).

A significant population decline has also been reported in Switzerland. A so-called abundance index was assessed during three national surveys from male counts at leks, direct observations and indirect evidence (e.g. footprints, droppings, feathers) of the species' presence (Mollet et al. 2003). The index numbers reported were a minimum of 
1,100 males in 1968-1971 (Glutz von Blotzheim et al. 1973), 600 in 1985 (Marti 1986) and 450-500 in 20012003 (Mollet et al. 2003). This decline in total abundance of capercaillie in Switzerland was related to the contraction and fragmentation of the distribution range (Mollet et al. 2003)

Male counts at leks are a widespread method to estimate the individual abundance in polygynous wildlife species. However, such assessments are biased because attendance at the lek sites is age-dependent. Capercaillie males older than 3-4 years tend to defend territories close to the lek centre, whereas younger males occupy peripheral territories or even show non-territorial behaviour during the mating season (Storch 1997; Wegge et al. 2003). Local ecological factors affecting the numbers of territorial males are well understood in capercaillie, and local abundance is estimated by simply doubling male counts, assuming an even sex ratio. However, the factors affecting the presence and numbers of non-territorial individuals are more complex to understand, which may cause biased indices of local abundance based on FS. The consequence of using biased and potentially inaccurate indices or estimates of population sizes may be to (1) fail to detect a demographic response of populations following management actions, (2) to invest human and financial resources to populations that are not currently threatened or (3) to elaborate inappropriate management scenarios.

In the present study, we compared two alternative approaches to estimate the sizes of eight local populations of capercaillie in the Alps and Prealps of central and eastern Switzerland. We first assessed indices of population sizes from the density and distribution of direct and indirect evidence of the species' presence recorded during extensive FS. In a second step, we genotyped the samples collected during FS and estimated the size of the local populations based on genetic tagging data (referred to as CMR). CMR estimates were calculated with an urn model to allow for single capture events. We studied how FS and CMR estimates relate to MNA, assessed by enumerating the number of unique genotypes at each study site. Our results demonstrate that FS consistently underestimated the sizes of local populations, while appropriate genetic CMR may improve the evaluation of population sizes in monitoring programs.

\section{Materials and methods}

Study species, sample collection and sample storage

In Switzerland, the capercaillie (T. urogallus) inhabits large coniferous forests of mountainous areas in the Jura, the central and eastern Prealps and the eastern Alps (Mollet et al. 2003; Fig. 1). Graf et al. (2005, 2006) developed a habitat model for the species based on presence/absence data and a set of environmental variables. The model was used to identify priority areas for the conservation of the capercaillie in the Swiss Alps and Prealps (Graf et al. 2004; Mollet et al. 2008). In the present study, we used the habitat model to divide our study area into discrete study sites, i.e. single forest patches or groups of neighbouring forest patches situated along valley slopes and belonging to
Fig. 1 Distribution range of the capercaillie in Switzerland (dark shadings) and division into five capercaillie regions (1-5) by putative barriers to dispersal, illustrated in light shadings (from Mollet et al. 2003). The locations of the eight study sites are delineated by ellipses. The capercaillie regions 3, $4 a$ and $4 b$ are situated in the central Prealps, the eastern Prealps and the central Alps, respectively

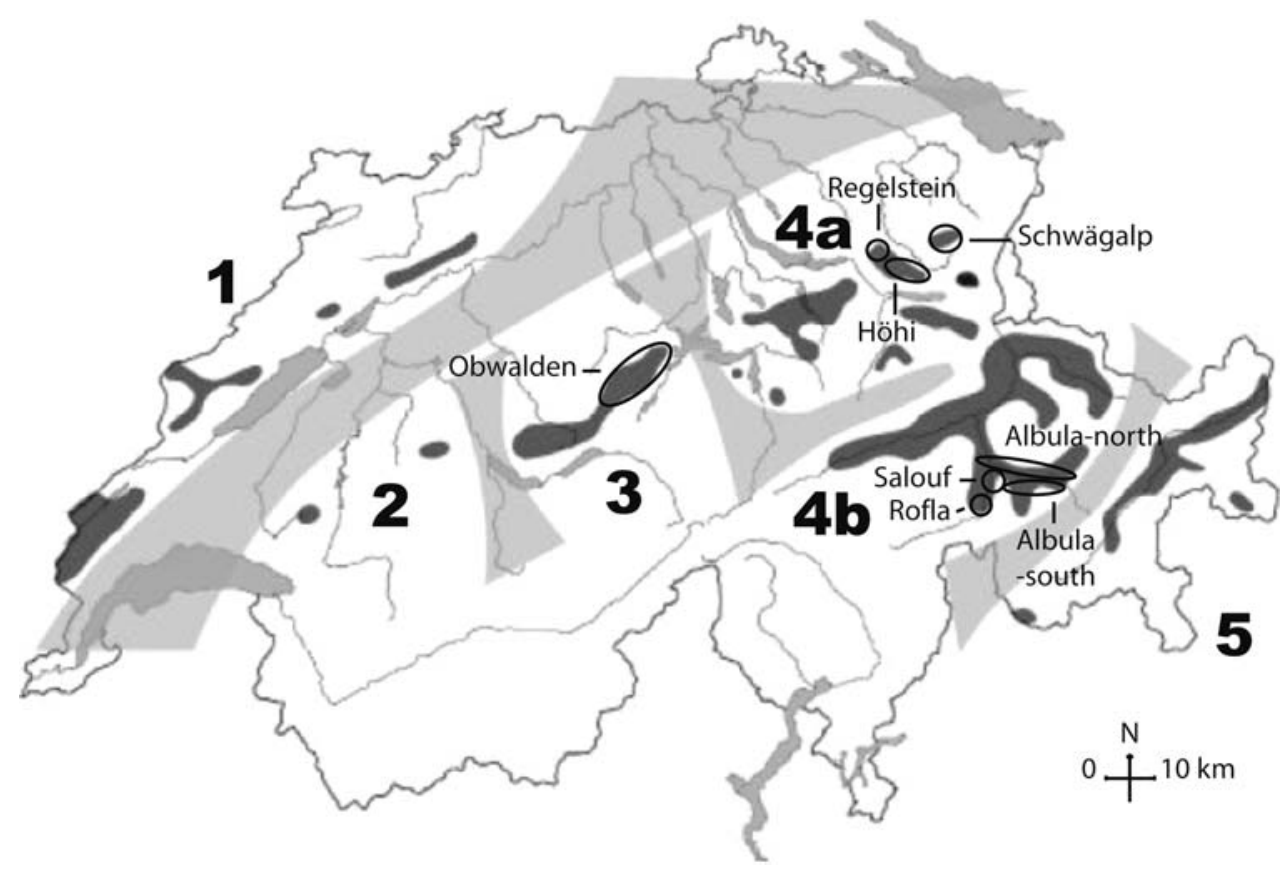


the same forest unit. We observed five or more individuals at most study sites. At the remaining study sites, only one or two individuals were found. Estimating the sizes of these local populations is irrelevant given the low number of samples collected and we therefore excluded all study sites where we observed less than five unique genotypes from further analyses. Eight study sites remained, namely Obwalden, Regelstein, Höhi, Schwägalp, Rofla, Salouf, Albula-north and Albula-south (Fig. 1). We used the term of local population to allocate the individuals found at each study site.

The study site Obwalden was situated in a mid-elevated mountain range (ca. 1,000-1,700 $\mathrm{m}$ a.s.l.) in the central Prealps. The habitat consisted mainly of large and contiguous areas of mature stands of coniferous forests dominated by Norway spruce [Picea abies (L.) Karst.] and Mountain pine (Pinus mugo Turra) interspersed with large mires. Two study sites in the eastern Prealps, Regelstein and Höhi, extended over forest-covered hilltops. The third study site in the eastern Prealps, Schwägalp, was situated east of a road pass and mostly consisted of the Southexposed slope of a mountain-valley system. The habitat in the eastern Prealps mainly consisted of coniferous forests dominated by Norway spruce and Common beech (Fagus sylvatica $\mathrm{L}$.) within a matrix of alpine grassland at altitudes from 1,000 to $1,800 \mathrm{~m}$ a.s.l. The study site Rofla was a large, forest-covered hillside with interspersed flat areas. The three other study sites in the central Alps, Salouf, Albula-north and Albula-south, were situated along the valley of the Albula river. In this area, the suitable habitat for the capercaillie extended along a forest band within the range 1,200-2,000 $\mathrm{m}$ a.s.l. These three study sites showed one main aspect each, north-east (Salouf), south (Albulanorth) and north (Albula-south) with Norway spruce, Scots pine (Pinus sylvestris L.) and Mountain pine as most abundant tree species.

The study areas were investigated in the years 2000 (Rofla), 2002 (Albula-south, Albula-north, Salouf), and 2003 [Regelstein, Höhi, Schwägalp (R. Debrunner, G. Jacob, K. Bollmann, unpublished report, 2005) and Obwalden]. We surveyed the study sites once during the late winter season, from February to May with a main focus during April-May when males and females aggregate around the leks in the core area of winter home ranges (Storch 2001). Lek areas are usually situated in open forest stands, clearings or fens. We focused our study on those forests where capercaillie presence had been reported in at least one of the national inventories of 1968-1971 (Glutz von Blotzheim et al. 1973) and 1985 (Marti 1986) or in a cantonal inventory that includes capercaillie data of the annual surveys of wildlife wardens. Fieldwork consisted of a systematic search for indirect (mainly faeces, feathers, and footprints) and direct (sightings) evidence of capercaillie presence along transects within the perimeter of any inventory in coniferous and mixed forest stands (Bollmann et al. 2005). There, we concentrated on searching for roosting and feeding trees, hiding sites, internal forest edges, root-plates and tree stumps (Bollmann et al. 2005; Bollmann and Graf 2008), since capercaillie use only few habitat components during winter (Klaus et al. 1989; Storch 2001).

For genetic analyses, we collected fresh $(\leq 2$ days old $)$ faeces and feathers found during FS. On the scale of a perimeter, we selected samples of each sex separated by a distance of at least $100 \mathrm{~m}$ to minimize repeated sampling of a particular individual. On the small scale, in the vicinity of lek areas, sampling was more intensive and directed towards the freshest faeces of the day of both sexes that were clustered around the lek centre. This procedure especially applies for the study areas of Rofla and Salouf. We assigned faeces to male or female individuals based on the size and shape of the faeces. The dry faeces of males are generally thicker $(>10 \mathrm{~mm})$ than those of females $(\leq 8-$ $9 \mathrm{~mm}$ ) (Klaus et al. 1989). Although not unambiguous, we used this method because it is the only one available to assign faecal samples to males or females in the field. Feather samples were confidently assigned to male or female individuals based on differences in pattern and coloration. Feathers were collected in paper envelopes or plastic bags (with or without silica gel). Faecal samples were collected and stored in $15-\mathrm{ml}$ plastic tubes filled with $\sim 5 \mathrm{ml}$ of silica gel, or simply air-dried. Samples were stored at room temperature or frozen at $-20^{\circ} \mathrm{C}$. At sites where several samples were collected, we selected the freshest samples, i.e. those samples with the greatest prospect of providing a complete genotype (Regnaut et al. 2005; G. Jacob, personal observation). Of the total sample analysed, $90 \%$ were faeces and $10 \%$ were feathers.

\section{DNA extraction and genotyping}

We extracted DNA in a room dedicated for DNA extraction, i.e. free of PCR-amplified DNA, and using aerosolresistant pipette tips throughout to avoid cross-sample contaminations. We included negative extraction controls, i.e. tubes in which the sample was replaced by distilled water, to check for cross-sample contaminations.

DNA was extracted using the DNA Stool MiniKit (Qiagen). All buffer and reagent names refer to material provided in the kit. A fragment of each dropping (0.2$0.5 \mathrm{~g}$ ) was incubated at room temperature for $12 \mathrm{~h}$ in $3 \mathrm{ml}$ buffer ASL to collect epithelial cells. After cleaning (InhibitEX tablet) and digestion (proteinase K), the DNA was bound to a silica membrane (QIAmp spin column) and washed with $500 \mu \mathrm{l}$ buffers AW1 and AW2. The DNA was eluted from the silica membrane using $2 \times 75 \mu \mathrm{l}$ buffer 
AE. DNA from feathers was extracted using the QIAmp Tissue Extraction Kit (Qiagen). The tip of a feather (0.5$1 \mathrm{~cm}$ ) was cut into small pieces and incubated over night at $37^{\circ} \mathrm{C}$ with proteinase $\mathrm{K}$, no cleaning step was done before digestion. DNA binding and washing was as above (DNeasy spin column). The DNA was eluted from the silica membrane using $2 \times 75 \mu \mathrm{l}$ buffer AE.

We amplified ten nuclear microsatellite loci developed for the capercaillie (Segelbacher et al. 2000) and two additional nuclear microsatellite loci, BG15 and BG18, developed for the black grouse (Tetrao tetrix L., Piertney and Höglund 2001). We distinguished between the three grouse species present in the study area, i.e. capercaillie, black grouse and hazel grouse (Bonasa bonasia L.) based on different allele size ranges at loci BG15 and BG18 ("Appendix"). The twelve microsatellite loci were amplified in four multiplex-PCRs, each containing three primer pairs differing in their fluorescent labelling dyes (FAM, HEX, NED; Applied Biosystems). We amplified a fragment of the chromo-helicase-DNA-binding (CHD) gene using the primer pair P2 and P8 of Griffiths et al. (1998) to identify the sex of the defecators. All PCRs were set up in $10 \mu \mathrm{l}$ volumes containing $1 \mu \mathrm{l}$ of DNA extract, $1 \times$ Multiplex Kit MasterMix (Qiagen), $1 \mathrm{mM} \mathrm{MgCl}_{2}, 0.1 \mu \mathrm{g} / \mu \mathrm{l}$ Bovine Serum Albumine (BSA) and $160 \mathrm{nM}$ of each primer. Amplifications were done on a PTC-100 thermocycler (MJ Research) with the following steps: an initial polymerase activation at $95^{\circ} \mathrm{C}$ for $15 \mathrm{~min}, 37$ cycles of $94^{\circ} \mathrm{C}$ for $30 \mathrm{~s}, 56^{\circ} \mathrm{C}$ (microsatellites) and $46^{\circ} \mathrm{C}$ (sex identification) for $120 \mathrm{~s}, 72^{\circ} \mathrm{C}$ for $30 \mathrm{~s}$, and a final extension at $72^{\circ} \mathrm{C}$ for $45 \mathrm{~min}$. Negative PCR controls, i.e. tubes in which DNA template was replaced by distilled water, were included throughout to check for contaminations during DNA extraction or PCR setup. The amplification products were visualized on an ABI3100-Avant automated sequencer (Applied Biosystems). The allele lengths were coded using GENESCAN 3.1 and GENOTYPER 2.5 (Applied Biosystems), relative to an internal size standard (ROX $400 \mathrm{HD}$, Applied Biosystems). We also loaded a reference sample as a positive control to check whether the electrophoretic mobility of the fragments was consistent among runs (Davison and Chiba 2003). We visualized the products of the sexing PCR on 3\% agarose gels as recommended by Griffiths et al. (1998). Two alleles differing in size, CHD-Z (330 bp) and CHD-W (380 bp), allow for the discrimination between heterozygous females ( $\mathrm{Z} / \mathrm{W})$ and homozygous males (Z/Z) (Segelbacher 2002).

We followed the multi-tube approach suggested by Navidi et al. (1992) and Taberlet et al. (1996), amplifying each DNA extract in four reactions. We first amplified loci BG15, TuD3 and TuT1 in one multiplexPCR to identify and exclude samples from black grouse and hazel grouse. A second locus, BG18, was used to distinguish among grouse species when locus BG15 failed to amplify. The genotype at each locus was recorded if the same allele combination was observed in three or more PCR replicates and left blank otherwise. Samples with one or two missing loci were amplified in four additional PCR replicates and their genotypes were recorded if the same allelic combination was observed in three out of eight replicates. Loci that could not be scored after eight PCR replicates were coded as missing values. Samples with a low prospect of producing a multi-locus genotype (no amplification products at any of the three loci) and those assigned to black grouse and hazel grouse were discarded. Capercaillie samples were typed with the nine remaining microsatellite markers, organised in three multiplex-PCRs, and the sex-specific locus following the same genotyping procedure. Only samples with $\geq 8$ loci unambiguously genotyped were retained for further analyses.

We considered two multi-locus genotypes to be identical if they shared all the alleles at all the loci, excluding loci with missing values. To reduce the chance of erroneously considering two genotypes as identical, respectively different, as a consequence of errors in the process of genotyping or recording of the data, we re-analysed those genotypes differing only because of missing values and those differing by a single allele. We considered that an allelic combination, which represents one or several identical genotypes, to be unique if it differed from all the other allelic combinations by at least two alleles (excluding missing values).

\section{Data analysis}

Field survey estimates of population sizes were derived from the frequency and distribution of fresh samples $(\leq 1$ day old) of male faeces or the abundance of clusters of male faeces around a lek centre. Direct observations of males and females along a survey transect were used to determine a minimum estimate. In survey perimeters with known lekking areas, each cluster of fresh male faeces counted as one male. In perimeters without a known lek, a roosting tree or hiding site with faeces of the day corresponded to one male. As we assumed a sex ratio of one to one for our study, we doubled the estimated number of males to obtain the FS estimate of a study site. In general, field estimates for the local populations at the eight study sites were derived from the number and distribution of spatially separate clusters of fresh faeces of both sexes. In cases were these numbers were smaller than the number of direct observations, the latter was used as minimal estimate for FS.

With the genetic data, we tested for deviation from Hardy-Weinberg equilibrium in the eight local populations 
using GENEPOP (Raymond and Rousset 1995). We used GIMLET (Valière 2002) to compute the probability of two individuals sharing the same genotype, $\mathrm{PI}_{\mathrm{sib}}$, as described by Taberlet and Luikart (1999). $\mathrm{PI}_{\text {sib }}$ accounts for the sampling of relatives and, thus, provides a more conservative measurement than the probability of identity between two individuals within the local populations, PI, proposed by Paetkau and Strobeck (1994). Values of $\mathrm{PI}_{\text {sib }}$ below 0.01 are recommended for studies of population sizes (Waits et al. 2001). We also calculated the number of alleles and the expected heterozygosity, $H_{\mathrm{e}}$, at each locus.

We estimated the sizes of the local populations from genetic tagging data, i.e. relying on the CMR concept, by using CAPWIRE, a program based on likelihood functions that describe an urn model with replacement (Miller et al. 2005). Two models are implemented that account for equal frequencies of capture among individuals (even capture model, ECM) or for different frequencies of capture among individuals (two innate rates model, TIRM). Confidence intervals were estimated using a parametric bootstrap procedure. Miller et al. (2005) recommend using the TIRM model in all cases. However, the ECM may perform better in some populations, and a likelihood-ratio test is implemented in CAPWIRE to choose the most appropriate model. We could not make a prior assumption about the distribution of the frequencies of capture of the individuals, as several factors potentially affect the distribution or attendance of capercaillie in the winter home ranges and the detection probability of the samples at the various study sites. We therefore estimated the sizes of the eight local populations using the most appropriate model as indicated by the likelihood-ratio test.

\section{Results}

\section{Multi-locus genotyping}

Overall, 185 (48\%) of the 384 samples analysed amplified at eight or more loci (Table 1). Within study sites, the genotyping success ranged from 26 (Salouf) to $73 \%$ (Höhi). Based on species-specific differences in allele sizes at loci BG15 and BG18, 178 genotypes were assigned to capercaillie (T. urogallus) and five to black grouse ( $T$. tetrix). Two genotypes showed alleles both in the size ranges characteristic of capercaillie and black grouse and were considered as hybrids. We identified no genotype indicative of hazel grouse (B. bonasia). The 178 capercaillie genotypes grouped into 104 unique allelic combinations. The probability of identity among them was below the threshold value of $0.01\left(\mathrm{PI}_{\text {sib }}=4.8 \times 10^{-4}\right)$. $\mathrm{PI}_{\text {sib }}$ values ranged from $4.0 \times 10^{-4}$ (Albula-north) to $3.6 \times 10^{-3}$ (Salouf). The average number of observations
Table 1 Summary of the genotyping process

\begin{tabular}{lccccc}
\hline Study sites & \multicolumn{1}{c}{$S$} & $N_{\text {genot }}$ & $\%$ & $N_{\text {Tu }}$ & $\mathrm{PI}_{\text {sib }}$ \\
\hline Obwalden & 95 & 46 & 48 & 41 & 0.0021 \\
Regelstein & 33 & 20 & 61 & 20 & 0.0025 \\
Höhi & 40 & 29 & 73 & 29 & 0.0015 \\
Schwägalp & 36 & 15 & 42 & 15 & 0.0012 \\
Rofla & 35 & 17 & 49 & 17 & 0.0032 \\
Salouf & 46 & 12 & 26 & 11 & 0.0036 \\
Albula-north & 66 & 36 & 55 & 36 & 0.0004 \\
Albula-south & 33 & 10 & 30 & 9 & 0.0005 \\
Total & 384 & 185 & 48 & 178 & 0.00041
\end{tabular}

We report for each study site and over all study sites (Total) the number of samples analysed, $S$, the number, $N_{\text {genot }}$, and percentage, $\%$, of samples genotyped at more than eight nuclear microsatellite loci, and the number of genotypes assigned to capercaillie, $N_{\mathrm{Tu}}$

We also report the probability of two individuals sharing the same genotype, $\mathrm{PI}_{\text {sib }}$ within each study site and over all study sites (see "Materials and methods" for details)

per individual within the eight study sites ranged from 1.1 (Albula-south) to 2.4 (Rofla; Table 2). The number of observations per individual ranged from one to four in males (mean $\pm \mathrm{SD}=1.9 \pm 1.1$ ) and one to six in females $(1.7 \pm 1.2)$. Identical genotypes were confined to one study site.

Amplification success of the CHD gene fragment used for the molecular sexing was lower than that of microsatellite loci. The size of the CHD gene fragment is twice the mean size of microsatellite fragments, which could explain the low success rate of the molecular sexing. Indeed, only 39 individuals could be sexed, of which 21 were males and 18 were females (Table 2). The sex of the individuals was assessed from the inspection of faeces only at Albula-south and Rofla, and from genetic results only at Regelstein, Höhi and Schwägalp. At the other study sites, the sex of eleven individuals was assessed with both methods. Ten out of eleven individuals were correctly assigned and one individual was erroneously identified as a male based on the inspection of faeces, assuming the genetic sex determination for that individual was correct.

The number of alleles per locus ranged from 3 (TuD3) to 12 (TuD5; mean number of alleles per locus $n=6.1$ ). The probability of two individuals sharing the same genotype at a locus, suggesting the presence of siblings, $\mathrm{PI}_{\text {sib }}$, ranged from 0.328 (TuD5) to 0.619 (TuD3; mean $\mathrm{PI}_{\mathrm{sib}}=0.466$ ).

Over all local populations, loci TuT1 and TuD6 deviated from HWE (data not shown) but we nonetheless kept them in the analyses (see "Discussion" for details). These two loci were the third $\left[\mathrm{PI}_{\text {sib }}(\mathrm{TuD6})=0.410\right]$ and the fifth $\left[\mathrm{PI}_{\mathrm{sib}}(\mathrm{TuT} 1)=0.463\right]$ most informative loci overall to discriminate among individuals. 
Table 2 Summary table of the indices/estimates of population sizes at the eight study sites

\begin{tabular}{|c|c|c|c|c|c|c|c|c|}
\hline \multirow[t]{2}{*}{ Study sites } & \multirow[t]{2}{*}{ MNA } & \multirow[t]{2}{*}{$n_{\mathrm{M}}$} & \multirow[t]{2}{*}{$n_{\mathrm{F}}$} & \multirow[t]{2}{*}{ Obs } & \multirow[t]{2}{*}{ Experience } & \multicolumn{3}{|c|}{ Index/estimate of population sizes } \\
\hline & & & & & & FS & CMR & Model \\
\hline Obwalden & 29 & $16(6)$ & $13(3)$ & 1.4 & $\mathrm{e}$ & $28(21-35)$ & $78(44-114)$ & TIRM \\
\hline Regelstein & 9 & (3) & (4) & 2.1 & $\mathrm{i}$ & $2(1-2)$ & $14(9-25)$ & TIRM \\
\hline Höhi & 16 & (7) & (7) & 1.9 & $\mathrm{i}$ & $4(2-4)$ & $20(16-26)$ & ECM \\
\hline Schwägalp & 7 & (3) & (4) & 2.1 & $\mathrm{e}$ & $6(6-7)$ & $10(7-19)$ & TIRM \\
\hline Rofla & 7 & 2 & 4 & 2.4 & $\mathrm{i}$ & $4(3-5)$ & $10(7-16)$ & TIRM \\
\hline Salouf & 5 & $5(1)$ & & 2.2 & $\mathrm{e}$ & $5(5-6)$ & $5(5-5)$ & ECM \\
\hline Albula-north & 23 & $13(1)$ & 9 & 1.6 & $\mathrm{e}$ & $21(17-29)$ & $36(24-51)$ & ECM \\
\hline Albula-south & 8 & 5 & 2 & 1.1 & $\mathrm{e}$ & $7(6-8)$ & $33(9-33)$ & ECM \\
\hline
\end{tabular}

Numbers in brackets indicate the confidence interval around the estimates (see "Materials and methods" for details)

We indicate for each study site the number of unique genotypes (minimum number alive, MNA), of which the number of those assigned to males, $n_{\mathrm{M}}$, and to females, $n_{\mathrm{F}}$, based on field evidence and based on molecular sexing (numbers in brackets), and the average frequency of detection per genotype, Obs (total number of samples successfully genotyped divided by the number of unique genotypes observed), and the experience of field workers ( $e$ experienced, $i$ inexperienced; see text for details)

We report for each study site the index of local population sizes assessed from direct and indirect evidence of the species' presence, FS, and the estimate of local population sizes calculated using the ECM or TRIM model in CAPWIRE, CMR

\section{Abundance indices}

Using the automatic model selection CAPWIRE, the ECM model appeared to perform best at Höhi, Salouf, Albulanorth and Albula-south. At these study sites, using ECM resulted in lower estimates of the abundance indices and narrower associated confidence intervals than using the TIRM model (data not shown).

The differences between CMR and MNA indices of abundance were greatest at Obwalden and Albula-south, the two study sites at which the number of CMR occasions per individual were lowest. The population size estimates from CMR equalled MNA at Salouf and were 1.3-1.6 times larger than MNA at Regelstein, Höhi, Schwägalp, Rofla and Albula-north. The confidence intervals around the CMR estimates of population sizes was null at Salouf, but large at the other study sites, ranging from $0.5 \mathrm{~N}$ at Höhi to $1.2 \mathrm{~N}$ at Schwägalp (Table 2).

Indices of population sizes from FS were close to MNA at Obwalden, Schwägalp, Salouf, Albula-north and Albulasouth, where experienced fieldworkers managed the surveys (Table 2). At these study sites, the upper limits of the confidence intervals were equal to or slightly larger (range 1.2-1.3) than MNA. At Regelstein, Höhi and Rofla, the indices of population sizes assessed from FS were 1.75-4.5 times lower than MNA.

\section{Discussion}

In the present study, we used a multiplex-PCR approach to genotype non-invasive samples collected during FS of capercaillie at eight study sites in the Swiss Alps and Prealps. We show that indices of population sizes inferred from FS underestimated local population sizes, while genetic analysis of the non-invasively collected samples (analogous to a capture-mark-recapture method without the need for capturing, marking and recapturing) may be a valuable alternative method to estimating the abundance of the capercaillie and other elusive species.

Genotyping and suitability of the markers

We established a strict genotyping procedure to limit the risk of cross-sample contaminations and genotyping errors, which might arise when working with degraded DNA (Vigilant 2002). Molecular genetic analyses of non-invasive samples are expensive and time-consuming. This may confine such analyses to the study of rare or endangered charismatic species, despite of their advantages (no physical capture of individuals, low disturbance of the investigated population). However, the quality and reliability of the genotypes may be maximised by optimizing the procedures for the collection and storage of the samples (Frantzen et al. 1998; Murphy et al. 2002; Nsubuga et al. 2004), and for DNA extraction (Horvath et al. 2005) and amplification protocols (multiplex-PCR). Achieving a high success of genotyping may contribute to decreasing the costs of molecular genetic analyses of non-invasive samples and to encourage ecologists using non-invasive sampling techniques in population studies.

Two loci, TuD6 and TuT1, deviated from HWE and showed a large proportion of missing values and a deficit in heterozygous individuals. Population structure or 
inbreeding in the population was unlikely given that only two out of twelve loci deviated from HWE. The observed deficit in heterozygous individuals may also result from a high rate of allelic dropout owing to the poor quality of the DNA used as template. However, we should have observed this pattern in other loci as well, which was not the case. This suggests that the deviation from HWE at loci TuD6 and TuT1 resulted from the presence of one or more null alleles. In addition, parentage analysis confirmed the presence of null alleles at these loci (data not shown). We kept them in the analyses because individual identification relies solely on the individual genotypic information and is therefore not affected by the occurrence of null alleles or by any cause of deviation of the allelic frequencies from HWE. However, null alleles may affect accurate estimation of the probability of identity.

Samples that differed in allelic combination by at least two alleles at two loci were unlikely from a single individual, i.e. resulting from genotyping errors. The probability that two individuals shared the same genotype was lower than the recommended threshold value of 0.001 (Mills et al. 2000), which suggests that our set of markers was powerful enough to discriminate between individuals and, thus, was suitable to investigate the local abundance of capercaillie at the eight study sites. Some loci had few alleles and showed low levels of expected heterozygosity. Additional microsatellite loci may be required to confidently distinguish among individuals and to accurately estimate local abundance in populations showing lower levels of genetic diversity than those observed in our study.

Our results suggest that sex determination from field evidence may provide a fast and straightforward method to assign faecal samples to males or females. Molecular sexing appears to be less ambiguous but its applicability is restricted by the poor quality of the DNA used as template, which limits the amplification success of large fragments (>380 bp) as in molecular sexing using the P2/P8 primer combination. Recently, alternative primer combinations have been suggested for bird sexing, amplifying shorter fragments with higher success rates in degenerated DNA, but these have not been tested for capercaillie or closely related taxa (Bantock et al. 2008). We also observed a rapid decrease in the success of the molecular sexing with the time elapsed between DNA extraction and amplification (data not shown). This observation indicates that DNA degraded even when stored in TE buffer and at $-20^{\circ} \mathrm{C}$. Thus, our results confirm that molecular sexing is achievable in capercaillie from faecal samples, while rapid processing of the samples after collection may improve the success and reliability of molecular sexing from noninvasive samples.
Suitability of the abundance index/estimator

Assuming that the entire study site was prospected (sampling effort of 100\%) and that all individuals were captured (probability of capture of one for all individuals), MNA would theoretically equal the true size of the population. However, under realistic sampling schemes, in particular for rare and elusive species, MNA will always be biased towards lower values. Consequently, any method that provides an index of population size equal to or lower than the MNA is probably also biased towards low values. This is the case for FS at the eight study sites (Table 2).

We did not reach the average of 2.5 observations per individual at any study site as recommended by Miller et al. (2005) to obtain estimates within a $15 \%$ range of the true population size, $N$. If the number of observations per individual is low, the confidence interval of the estimated $N$ obviously must increase (Miller et al. 2005). In addition, the urn model implemented in CAPWIRE tends to overestimate population size when the heterogeneity of capture is low (Miller et al. 2005), as observed at Obwalden and Albula-south. According to Miller et al. (2005), the 1.6 and 2.4 observations made on average per individual at Albulanorth and Rofla, respectively, provide estimates that are within a 30 or $20 \%$ range of the true population sizes, respectively. Thus, although the level of accuracy obtained in our study is not optimal, our results suggest that methods based on collected feathers and faeces may provide more valuable estimates of population sizes in capercaillie than other estimators.

Studies based on non-invasive sampling and genetic analyses in two elusive species, the giant panda (Ailuropoda melanoleuca David) and the fishotter (Lutra lutra L.), provided estimates twice as large as indices of population sizes assessed from previous surveys based on the observations of evidence of the species' presence (Hung et al. 2004; Zhan et al. 2006). Two factors may explain these differences. First, assigning non-invasive samples to an individual is far more accurate based on genotypic information than based on indirect evidence of presence (e.g. feathers, faeces, footprints), which may at best provide information on the sex or the age (adult or juvenile) of the individuals. Second, non-territorial individuals exploit habitat that may not be recognised as typical for the species or may use home ranges together with other individuals. FS may hardly reveal such spatial clustering in non-territorial species because indirect evidence of a species' presence rarely shows individual traits. This point may be particularly important for indices of capercaillie abundance because individuals of both sexes share home ranges during winter (Wegge and Rolstad 1986; Gjerde and Wegge 1989) and males' winter ranges cluster around leks (Storch 1997). 
Our sampling followed a standard protocol to control for differences in prospecting and sampling effort among sites. This procedure ensured that results could be reasonably compared among sites. We show that genotyping the samples collected improved the estimation of population sizes as compared to FS. In addition, our results suggest that individual experience and knowledge of the study area influenced the indices of local abundance assessed from direct and indirect evidence of the species. Field workers with two or three years of experience in our study (those recognised as experienced; Table 2) were able to differentiate the indirect evidence in the field more accurately whereas those with one year of experience tended to assess population size estimates much more conservatively. We therefore judge genetic analyses of non-invasive samples to be superior over field estimates (given 2-3 genotypings per individual can be obtained) and recommend this new approach as promising method to better estimate the abundance of cryptic animals living in forest habitats.

Implications for management programs

In this study, we compared two approaches to assess the size of eight local populations of capercaillie in the Swiss Alps. Our results suggest that the prior knowledge of the winter ecology of capercaillie and its habitat requirements positively influenced the accuracy of the indices of local population sizes assessed from FS and, consequently, of MNA and CMR estimators. Habitat requirements of the capercaillie were investigated on different spatial scales in the central Alps and Prealps (Graf et al. 2004, 2005; Bollmann et al. 2005), which improved the accuracy of the abundance index assessed from FS of experienced field workers. Still, the knowledge about the habitat requirements of females is limited, and direct observations of females are rare during traditional surveys (Glutz von Blotzheim et al. 1973; Marti 1986; Mollet et al. 2003). In our study, neither the number of individuals nor the number of samples collected per individual markedly differed between sexes. This result contrasts with the marked bias towards males in direct observations and lek counts. Thus, population size estimates based on direct and indirect evidence of both sexes and collected by experienced field workers would improve the estimates of local abundance of the species or, in other terms, approach the population size estimates obtained by genetic CMR.

We found larger numbers of capercaillie than expected, which suggests that the risk of local extinction of the species in the short term is lower than previously estimated. Genetic CMR might not be applicable for a rangewide, national survey of the species because of the costs associated with multi-locus genotyping of non-invasively collected faeces samples. We therefore recommend to monitor a subset of study sites using genetic CMR studies. This subset should represent the geographic and ecological variability of habitats within the distribution range of the species and include both core and edge populations. Such a monitoring program may further reveal the response of capercaillie to conservation measures, such as the conservation and improvement of habitat quality of occupied and unoccupied patches, respectively, or the restoration of patch connectivity between main regions of capercaillie distribution. Indeed, the species remains at risk of local extinction in the mid-term if no conservation measures are planned to reverse the loss and deterioration of suitable habitat.

The difference in the level of expertise between volunteers potentially impacts the results of presence/absence surveys of rare or elusive species (Kéry 2002). This bias may be limited if volunteers have the opportunity to train and acquire more experience in species identification and fieldwork (Darwall and Dulvy 1996). Even more so, inferring the abundance of a species is a complex task that requires some prior knowledge of the target species' biology, experience with fieldwork and knowledge of the factors affecting the density of the species (Foster-Smith and Evans 2003). The work of volunteers may still be valuable in genetic studies because sampling does not require particular skills and the efficiency of fieldworkers mostly depends on their knowledge of the field sites and sampling protocol and their experience in fieldwork. Noninvasive genetic studies may benefit from the help of game wardens, hunters or experienced volunteers, as exemplified in Bellemain et al. (2005) or in our present study.

Species-habitat relationships do influence abundance estimates and monitoring programs of target species due to imperfect detectability (Royle et al. 2005). This increases the risk that the status of rare and elusive species is inappropriately assessed and decision-making in management and conservation programs is hampered. Also other comparisons of indices of abundance based on genetic tagging and FS suggest that experts tend to underestimate the abundance of rare or elusive species (Hung et al. 2004; Zhan et al. 2006). Assessing the populations of endangered species using genetic techniques (Schwartz et al. 2006) may provide essential data for the monitoring of conservation actions and bridge the gap between biased field observations and the need for sound population estimates.

Acknowledgments Discussions with $\mathrm{N}$. Valière and comments from the associate editor and anonymous reviewers contributed to improve the scope of this manuscript. G. Jacob was financed by the MAVA foundation, and additional funding (R. Debrunner) was obtained from the canton of St Gallen (Amt für Jagd und Fischerei). K. Bollmann was financed by the Federal Office for the Environment FOEN and by the Swiss National Science Foundation (grant no. 3100-0655199). 


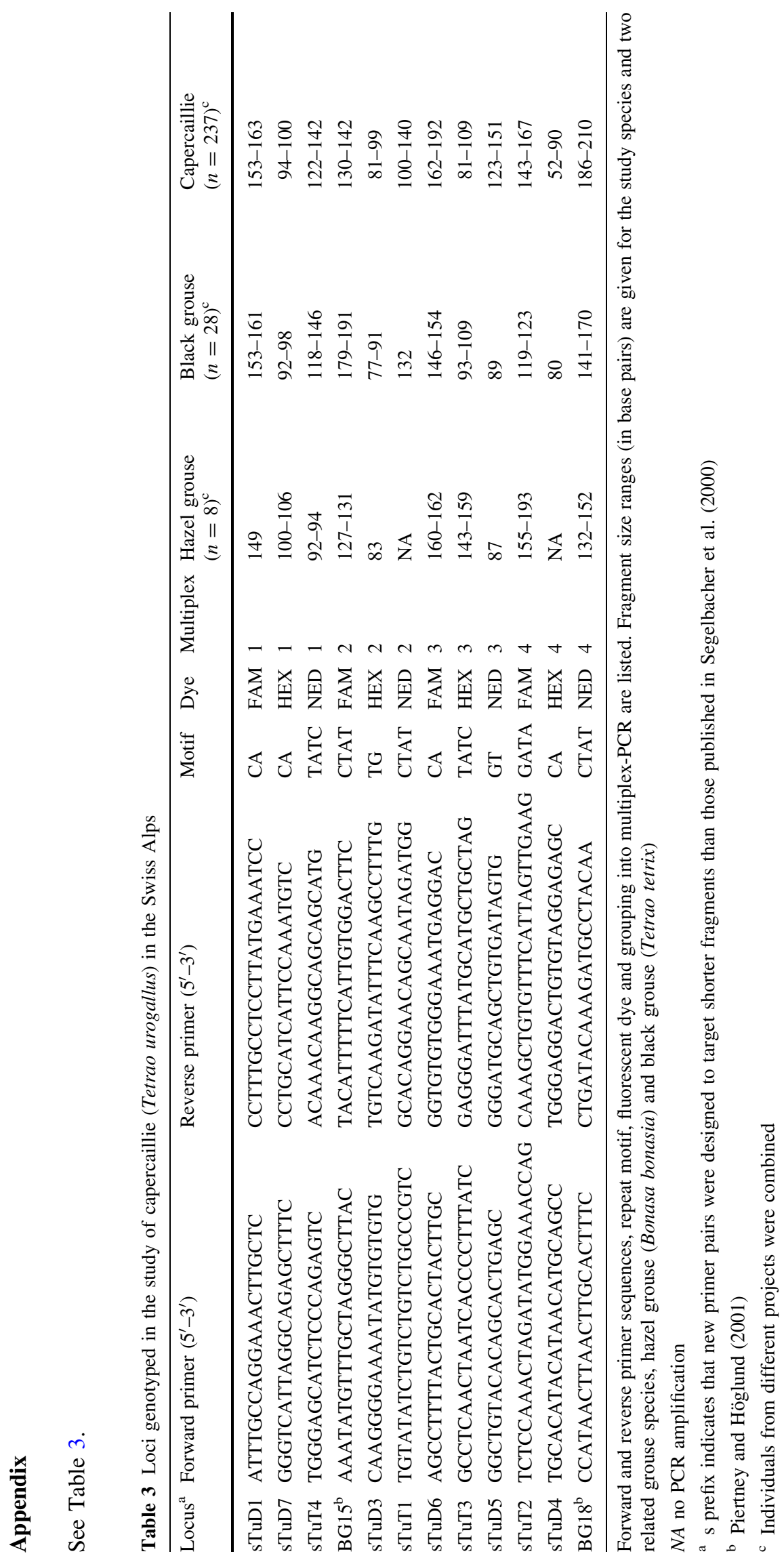




\section{References}

Allendorf FW, Luikart G (2007) Conservation and the genetics of populations. Blackwell, Malden

Banks SC, Hoyle SD, Horsup A, Sunnucks P, Taylor AC (2003) Demographic monitoring of an entire species (the northern hairy-nosed wombat, Lasiorhinus krefftii) by genetic analysis of non-invasively collected material. Anim Conserv 6:101-107. doi:10.1017/S1367943003003135

Bantock TM, Prys-Jones RP, Lee PLM (2008) New and improved molecular sexing methods for museum bird specimens. Mol Ecol Res 8:519-528. doi:10.1111/j.1471-8286.2007.01999.x

Bellemain E, Swenson JE, Tallmon O, Brunberg S, Taberlet P (2005) Estimating population size of elusive animals with DNA from hunter-collected feces: four methods for brown bears. Conserv Biol 19:150-161. doi:10.1111/j.1523-1739.2005.00549.x

Bollmann K, Graf RF (2008) Wie beeinflussen Lebensraumangebot und -fragmentierung die Verbreitung von Lokalpopulationen beim Auerhun. Ornithol Beob 105:45-52

Bollmann K, Weibel P, Graf RF (2005) An analysis of central Alpine capercaillie spring habitat at the forest stand scale. For Ecol Manage 215:307-318. doi:10.1016/j.foreco.2005.05.019

Bollmann K, Jenni L, Perrin N, Suter W (2008) Naturschutzforschung am Auerhuhn in der Schweiz: eine Übersicht. Ornithol Beob 105:5-17

Bradley BJ, Vigilant L (2002) False alleles derived from microbial DNA pose a potential source of error in microsatellite genotyping of DNA from faeces. Mol Ecol Notes 2:602-605. doi: 10.1046/j.1471-8286.2002.00302.x

Bromaghin JF (2007) The genetic mark-recapture likelihood function of capwire. Mol Ecol 16:4883-4884. doi:10.1111/j.1365-294X. 2007.03518.x

Darwall WRT, Dulvy NK (1996) An evaluation of the suitability of non-specialist volunteer researchers for coral reef fish surveys. Mafia Islands, Tanzania-a case study. Biol Conserv 78:223 231. doi:10.1016/0006-3207(95)00147-6

Davison A, Chiba S (2003) Laboratory temperature variation is a previously unrecognized source of genotyping error during capillary electrophoresis. Mol Ecol Notes 3:321-323. doi: 10.1046/j.1471-8286.2003.00418.x

Eggert LS, Eggert JA, Woodruff DS (2003) Estimating population size for elusive animals: the forest elephant of Kakum National Park, Ghana. Mol Ecol 12:1389-1402. doi:10.1046/j.1365-294X. 2003.01822.x

Fisher DO, Hoyle SD, Blomberg SP (2000) Population dynamics and survival of an endangered wallaby: a comparison of four methods. Ecol Appl 10:901-910. doi:10.1890/1051-0761(2000) 010[0901:PDASOA]2.0.CO;2

Foster-Smith J, Evans SM (2003) The value of marine ecological data collected by volunteers. Biol Conserv 113:199-213. doi: 10.1016/S0006-3207(02)00373-7

Frantz AC, Schaul M, Pope LC, Fack F, Schley L, Muller CP, Roper TJ (2004) Estimating population size by genotyping remotely plucked hair: the Eurasian badger. J Appl Ecol 41:985-995. doi: 10.1111/j.0021-8901.2004.00951.x

Frantzen MAJ, Silk JB, Ferguson JWH, Wayne RK, Kohn MH (1998) Empirical evaluation of preservation methods for faecal DNA. Mol Ecol 7:1423-1428. doi:10.1046/j.1365-294x.1998.00449.x

Franzreb KE (1997) Success of intensive management of a critically imperiled population of Red-cockaded Woodpeckers in South Carolina. J Field Ornithol 68:458-470

Fujiwara M, Caswell H (2001) Demography of the endangered North Atlantic right whale. Nature 414:537-541. doi:10.1038/35107054

Gagneux P, Boesch C, Woodruff DS (1997) Microsatellite scoring errors associated with noninvasive genotyping based on nuclear
DNA amplified from shed hair. Mol Ecol 6:861-868. doi: 10.1111/j.1365-294X.1997.tb00140.x

Gerloff U, Schlötterer C, Rassmann K, Rambold I, Hohmann G, Fruth B, Tautz D (1995) Amplification of hypervariable simple sequence repeats (microsatellites) from excremental DNA of wild living Bonobos (Pan paniscus). Mol Ecol 4:515-518. doi: 10.1111/j.1365-294X.1995.tb00247.x

Gjerde I, Wegge P (1989) Spacing pattern, habitat use and survival of capercaillie, Tetrao urogallus L., during winter in a fragmented boreal forest. Ornis Scand 20:219-225. doi:10.2307/3676916

Glutz von Blotzheim UN, Bauer KM, Bezzel E (1973) Tetrao urogallus. In: Glutz von Blotzheim UN (ed) Handbuch der Vögel Mitteleuropas, vol 5: Galliformes und Gruiformes. Akademische Verlagsgesellschaft, Wiesbaden, pp 172-225

Goossens B, Chikhi L, Utami SS, de Ruiter J, Brudford MW (2000) A multi-samples, multi-extracts approach for microsatellite analysis of faecal samples in an arboreal ape. Conserv Genet 1:157162. doi:10.1023/A:1026535006318

Graf RF, Bollmann K, Suter W, Bugmann H (2004) Using a multiscale model for identifying priority areas in capercaillie (Tetrao urogallus) conservation. In: Smithers $\mathrm{R}$ (ed) Proceedings of the 12th annual IALE (UK) conference "Landscape ecology of trees and forests". Cirencester, pp 84-90

Graf RF, Bollmann K, Suter W, Bugmann H (2005) The importance of spatial scale in habitats model: capercaillie in the Swiss Alps. Landscape Ecol 20:703-717. doi:10.1007/s10980-005-0063-7

Graf RF, Bollmann K, Suter W, Bugmann H (2006) On the generality of habitat suitability models: a case study of the capercaillie in three Swiss regions. Ecography 29:319-328. doi:10.1111/j.2006. 0906-7590.04328.x

Griffiths R, Double MC, Orr K, Dawson RJG (1998) A DNA test to sex most birds. Mol Ecol 7:1071-1075. doi:10.1046/j.1365294x.1998.00389.x

Hansen H, Ben-David M, McDonald DB (2008) Effects of genotyping protocols on success and errors in identifying individual river otters (Lontra canadensis) from their faeces. Mol Ecol Res 8:282-289. doi:10.1111/j.1471-8286.2007.01992.x

Helle P, Helle T, Lindén H (1994) Capercaillie (Tetrao urogallus) lekking sites in fragmented Finnish forest landscape. Scand J For Res 9:386-396. doi:10.1080/02827589409382856

Horvath MB, Martinez-Cruz B, Negro JJ, Kalmar L, Godoy JA (2005) An overlooked DNA source for non-invasive genetic analysis in birds. J Avian Biol 36:84-88. doi:10.1111/j.09088857.2005.03370.x

Hung CM, Li SH, Lee LL (2004) Faecal DNA typing to determine the abundance and spatial organisation of otters (Lutra lutra) along two stream systems in Kinmen. Anim Conserv 7:301-311. doi: $10.1017 / \mathrm{S} 1367943004001453$

Kéry M (2002) Inferring the absence of a species: a case study of snakes. J Wildl Manage 66:330-338. doi:10.2307/3803165

Klaus S, Andreev AV, Bergmann H-H, Müller F, Porkert J, Wiesner J (1989) Die Auerhühner. Westarp Wissenschaften, Magdeburg Die Neue Brehm-Bucherei (ed)

Kohn MH, York EC, Kamradt DA, Haugt G, Sauvajot RM, Wayne RK (1999) Estimating population size by genotyping faeces. Proc R Soc Lond B Biol Sci 266:657-663. doi:10.1098/rspb.1999.0686

Lukacs PM, Burnham KP (2005a) Estimating population size from DNA-based closed capture-recapture data incorporating genotyping error. J Wildl Manage 69:396-403. doi:10.2193/0022541X (2005)069<0396:EPSFDC $>2.0 . \mathrm{CO} ; 2$

Lukacs PM, Burnham KP (2005b) Review of capture-recapture methods applicable to noninvasive genetic sampling. Mol Ecol 14:3909-3919. doi:10.1111/j.1365-294X.2005.02717.x

Marti C (1986) Verbreitung und Bestand des Auerhuhns Tetrao urogallus in der Schweiz. Ornithol Beob 83:67-70 
Maschinski J, Frye R, Rutman S (1997) Demography and population viability of an endangered plant species before and after protection from trampling. Conserv Biol 11:990-999. doi: 10.1046/j.1523-1739.1997.96159.x

Miller CR, Joyce P, Waits LP (2005) A new method for estimating the size of small populations from genetic mark-recapture data. Mol Ecol 14:1991-2005. doi:10.1111/j.1365-294X.2005.02577.x

Miller CR, Joyce P, Waits LP (2007) Ordered vs, unordered samples: response to Bromaghin. Mol Ecol 16:4885. doi:10.1111/j.1365294X.2007.03583.X

Mills LS, Citta JJ, Lair KP, Schwartz MK, Tallmon DA (2000) Estimating animal abundance using noninvasive DNA sampling: promise and pitfalls. Ecol Appl 10:283-294. doi:10.1890/10510761(2000)010[0283:EAAUND]2.0.CO;2

Mollet P, Badilatti B, Bollmann K, Graf RF, Hess R, Jenny H, Mulhauser B, Perrenoud A, Rudmann F, Sachot S, Studer J (2003) Verbreitung und Bestand des Auerhuhns (Tetrao urogallus) in der Schweiz 2001 und ihre Veränderung im 19. und 20. Jahrhundert Ornithol Beob 100:67-86

Mollet P, Stadler B, Bollmann K (2008) Aktionsplan Auerhuhn Schweiz. Bundesamt für Umwelt (BAFU), Schweizerische Vogelwarte und Schweizer Vogelschutz SVS/BirdLife Schweiz, Bern

Morin PA, Wallis J, Moore JJ, Chakraborty R, Woodruff DS (1993) Noninvasive sampling and DNA amplification for paternity exclusion, community structure, and phylogeography in wild chimpanzees. Primates 34:347-356. doi:10.1007/BF02382630

Murphy MA, Waits LP, Kendall KC, Wasser SK JAH, Bogden R (2002) An evaluation of long term preservation methods for brown bear (Ursus arctos) faecal DNA samples. Conserv Genet 3:435-440. doi:10.1023/A:1020503330767

Navidi W, Arnheim N, Waterman M (1992) A multiple-tubes approach for accurate genotyping of very small DNA samples using PCR: statistical considerations. Am J Hum Genet 50:347-359

Nsubuga AM, Robbins MM, Roeder AD, Morin PA, Boesch C, Vigilant L (2004) Factors affecting the amount of genomic DNA extracted from ape faeces and the identification of an improved sample storage method. Mol Ecol 13:2089-2094. doi:10.1111/ j.1365-294X.2004.02207.x

Paetkau D, Strobeck C (1994) Microsatellite analysis of genetic variation in black bear populations. Mol Ecol 3:489-495. doi: 10.1111/j.1365-294X.1994.tb00127.x

Piertney SB, Höglund J (2001) Polymorphic microsatellite DNA markers in black grouse (Tetrao tetrix). Mol Ecol Notes 1:303304. doi:10.1046/j.1471-8278.2001.00118.x

Raymond M, Rousset F (1995) GENEPOP (version 1.2): population genetics software for exact tests and ecumenicism. J Hered $86: 248-249$

Regnaut S, Lucas FS, Fumagalli L (2005) DNA degradation in avian faecal samples and feasibility of non-invasive genetic studies of threatened capercaillie populations. Conserv Genet 7:449-453. doi:10.1007/s10592-005-9023-7

Royle JA, Nichols JD, Kéry M (2005) Modelling occurence and abundance of species when detection is imperfect. Oikos 110:353-359. doi:10.1111/j.0030-1299.2005.13534.x
Schwartz MK, Luikart G, Waples RS (2006) Genetic monitoring as a promising tool for conservation and management. Trends Ecol Evol 22:25-33. doi:10.1016/j.tree.2006.08.009

Schwarz CJ, Seber GAF (1999) Estimating animal abundance. Stat Sci 14:427-456. doi:10.1214/ss/1009212521 Review III

Segelbacher G (2002) Noninvasive genetic analysis in birds: testing the reliability of feather samples. Mol Ecol Notes 2:367-369. doi:10.1046/j.1471-8286.2002.00180.x

Segelbacher G, Paxton RJ, Steinbrück G, Trontelj P, Storch I (2000) Characterization of microsatellites in capercaillie Tetrao urogallus. Mol Ecol 9:1934-1935. doi:10.1046/j.1365-294x.2000. 0090111934.x

Storch I (1997) Male territoriality, female range use, and spatial organisation of capercaillie Tetrao urogallus leks. Wildl Biol 3:149-161

Storch I (2000) Grouse Status Survey and Conservation Action Plan 2000-2004 (ed. Group WBSGS). IUCN/The World Pheasant Association, Gland, Cambridge/Reading, $112 \mathrm{pp}$

Storch I (2001) Tetrao urogallus Capercaillie. BWP Update 3:1-24

Taberlet P, Luikart G (1999) Non-invasive genetic sampling and individual identification. Biol J Linn Soc Lond 68:41-55. doi: 10.1111/j.1095-8312.1999.tb01157.x

Taberlet P, Griffin S, Goosens B, Questiau S, Manceau V, Escaravage N, Waits LP, Bouvet J (1996) Reliable genotyping of samples with very low DNA quantity using PCR. Nucleic Acids Res 24:3189-3194. doi:10.1093/nar/24.16.3189

Valière N (2002) GIMLET: a computer program for analysing genetic individual identification data. Mol Ecol Notes 2:377-379. doi: 10.1046/j.1471-8286.2002.00228.x

Vigilant L (2002) Technical challenges in the microsatellite genotyping of a wild chimpanzee population using faeces. Evol Anthropol S1:162-165. doi:10.1002/evan.10082

Waits LP, Luikart G, Taberlet P (2001) Estimating the probability of identity among genotypes in natural populations: cautions and guidelines. Mol Ecol 10:249-256. doi:10.1046/j.1365-294X. 2001.01185.x

Wegge P, Rolstad J (1986) Size and spacing of capercaillie leks in relation to social behavior and habitat. Behav Ecol Sociobiol 19:401-408. doi:10.1007/BF00300542

Wegge P, Kvalsgard T, Hjeljord O, Sivkov AV (2003) Spring spacing behaviour of capercaillie Tetrao urogallus males does not limit numbers at leks. Wildl Biol 9:283-289

Wilson GJ, Frantz AC, Pope LC, Roper TJ, Burke TA, Cheeseman CL, Delahay RJ (2003) Estimation of badger abundance using faecal DNA typing. J Appl Ecol 40:658-666. doi:10.1046/ j.1365-2664.2003.00835.x

Zhan XJ, Li M, Zhang ZJ, Goossens B, Chen YP, Wang HJ, Bruford MW, Wei FW (2006) Molecular censusing doubles giant panda population estimate in a key nature reserve. Curr Biol 16:R451R452. doi:10.1016/j.cub.2006.05.042 